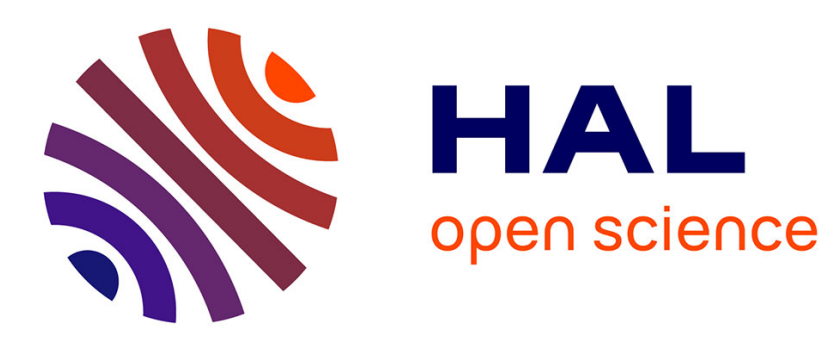

\title{
Study on China-Laos Forestry Cross-Border Cooperation Strategy Model
}

$\mathrm{Yu} \mathrm{He}$

\section{To cite this version:}

Yu He. Study on China-Laos Forestry Cross-Border Cooperation Strategy Model. 10th International Conference on Computer and Computing Technologies in Agriculture (CCTA), Oct 2016, Dongying, China. pp.396-405, 10.1007/978-3-030-06155-5_40. hal-02179959

\section{HAL Id: hal-02179959 \\ https://hal.inria.fr/hal-02179959}

Submitted on 11 Jul 2019

HAL is a multi-disciplinary open access archive for the deposit and dissemination of scientific research documents, whether they are published or not. The documents may come from teaching and research institutions in France or abroad, or from public or private research centers.
L'archive ouverte pluridisciplinaire HAL, est destinée au dépôt et à la diffusion de documents scientifiques de niveau recherche, publiés ou non, émanant des établissements d'enseignement et de recherche français ou étrangers, des laboratoires publics ou privés. 


\title{
Study on China-Laos Forestry Cross-Border Cooperation Strategy Model
}

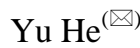 \\ Business School, Hohai University, Nanjing, Jiangsu, China \\ \{hhuheyu@163.com\}
}

\begin{abstract}
Natural resources are the basic elements of economic development. Laos is rich in forest resources, while the technology is backward. On the contrary, the forest resources of China which can be developed and used are less and the developing technology is advanced. In this case, the construction of "One Belt And One Road" provides a lot of opportunities to these two countries on cooperation. This paper analyzes the synergetic dynamics of forestry cross-border coordination strategy and puts forward the "Overseas Jiangsu" mode of forestry cross-border coordination strategy. This paper establishes the framework of cross-border collaborative cloud platform for forestry and analyzes the characteristics of cross-border coordination strategy. Lastly, this paper puts forward the relevant policy recommendations.
\end{abstract}

Key Words: Forestry; Cross-border coordination strategy; Cloud platform; Overseas Jiangsu.

\section{Introduction}

The forest is one of the most important natural resources of Laos. In 1940, the forest area reached 16.478 million $\mathrm{hm}^{2}$, occupying $70 \%$ of its national land area. However, in 1995, the number of the forest area felled to 12.435 million $\mathrm{hm}^{2}$, and the forest coverage rate fallen to $53.9 \%$, as a result of the population growth, wars, shifting cultivation, forest fires, irrational logging, etc. Forestry in Laos has been playing a decisive role all long, in terms of Laotian national economy and the basic livelihood of Laotian farmers. After three development stages of before the 1980's, 1980 's to 1990 's and 1990's to date, Forestry industry in Laos has been generally formed a production and operation pattern, which regards the multiple forest resources development and utilization as the main line. However, due to the Laotian underdeveloped economic, science and technology, the forest resources failed to maximize their potential, and the forestry industry failed to form industrial advantages. Forestry industry in Laos has always been dominated by a single timber production, with a single product structure, a high proportion of primary products, and an inability of producing the secondary products. The development of forestry industry and diversified economy cannot get rid of the dependence on forest resources.

China now has a low coverage rate of forest resources, namely its forest resources available for development and utilization is very limited. While the condition of Chinese economic is relatively developed and its information technology has developed rapidly. In addition, its technology of forestry development and utilization is relatively advanced. Moreover, due to the deterioration of Chinese ecological environment, the Chinese government has continuously strengthened the afforestation.

Xi Jinping, Chinese President, proposed the construction of a strategy named 
"One Belt And One Road ", which provided an opportunity for forestry cooperation between Laos and China. Cross-border collaboration strategy mainly focuses on the strategic matching problem of "Subject - Factor" in the area of international cooperation, and emphasizes the full mobilization of talent, capital, information, technology, resources and other factors on the basis of mutual benefits to achieve the complementary advantages between countries by re-integrating their respective advantages of resources. Laos and China have different levels of economic development. So the mode of forestry cooperation between Laos and China cannot simply copy the international experience. This paper builds a personalized cross-border collaborative strategic model by using the cloud service technology and the in-depth study of the regular pattern.

\section{Literature Review}

Ansoff, who is the originator of strategic management, puts up the concept of collaborative in the book "Corporate Strategy" in 1965. He pointed out that company strategies were made up of four elements which is the scope of product market, direction of growth, competitive advantages and synergy ${ }^{[1]}$. German physicist Haken founded the synergetic in the 1970s, and in his point of view, the synergetic was "the study of coordination and cooperation". And he thought the main research of synergetic was to study how to produce synergies between subsystems through interaction, and constitute a certain function of self-organization and composite systems (Haken, 1989, 2005) $)^{[2-3]}$ With the development of computer technology, it provides the technical support to the study of synergetic. Irene Greif and Paul Cashman (1988) ${ }^{[4]}$ firstly put forward the concept of "computer supported cooperative work (CSCW)". Now cloud computing, and semantic web technologies are applied to collaborative innovation platform by the scholars at home and abroad, and many research results have been obtained.

In the study of economic management, the scarcity of resource forces enterprises to obtain the resources through trade cooperation, then the enterprises can create and develop its internal resources through this way. Forest is the most basic natural resources, and the synergetic is applied to the field of forestry industry extensively. In Zhao-Juwan's point, the development of forestry ecological system and forestry industry system was relatively slow and there lacked a link between the "two systems". The core issue of China's forestry development is to solve the problems of the "two system", which is coordinated development and coordinated operation (Zhao-Junwang, 2001) ${ }^{[5]}$.From the perspective of supply and demand coordination, Jam-ming YANG, Zhi-guang ZHANG (2010) ${ }^{[6]}$ put forward chain extension and expansion model of the forestry industry, which discussed the longitudinal extension, transverse, factors demand and supply of forest products in the forestry industry chain, and puts forward the relevant policy recommendations. Yang Fan, Shi-tong Zhao, Wei-wei Huang $(2015)^{[7]}$ empirically studied collaborative development performance of the composite system after the collective forest right system reform of forestry by using complex system coordination degree model. Their research showed that the complex system of forestry cooperative is not high, but it is on the rise, at the same time they also put forward the related suggestions to improve the coordinated development of the forestry modernization.

With the rapid development of computer technology, it has been widely used in all walks of life in the economic development. Deng-Luli $(2016)^{[8]}$ summarizes the application of computer technology in forestry economic management, it says that the application of computer technology makes the development of forestry economy gradually reasonable, accurate and intelligent. Vivek $(2000)^{[9]}$ has developed a decision support system for the sustainable management of forest 
resource with GIS technology. It has realized the integration of many spatial and temporal variables, and it can be used to evaluate the sustainable forest management with multi rules. Mann et al, (2009) ${ }^{[10]}$ has developed the goods volume accounting system through the collection of relevant data on trees and making a model on it. It can be used to estimate specified tree height diameter, specific diameter, merchantable volume and total volume.

The academia has no explicit definition about the cross-border cooperation strategy and the research on cross-border cooperation strategy mainly focused on multinational companies and industries. Qi-Mingzhu $(2004)^{[11]}$ believes that the economic entity creates synergies through cross-border activities, just as substantive means to form their core competitiveness and also the main form of value creation of collaborative. Chun-Zhiwang, GaoQiang, Heiko (2015) ${ }^{[12]}$ using grounded theory to study the cross-border cooperation, with the use of a wide range of investigation and analysis means, making the German textile machinery manufacturing enterprise as an example, refining and analyzing the cooperative system elements, relations and structure of cross-border, finally proposed cross-border logistics collaboration system concept model.

Laos and China are adjacent to each other by water. From the view of resource endowment, they are different in the abundance of forestry resources, technology, market and capital, and they can use their own advantage of production elements to promote complementary cooperation. There is rarely research on forestry cooperation between Laos and China, so this paper intends to use the concept of cross-border collaborative and technology of cloud services to study Chinese forestry cross-border joint development with Laos.

\section{Synergy dynamics of forestry cross border cooperation strategy in Laos and China}

\subsection{Laos's reform and opening up provide conditions for cross-border cooperation in forestry between Laos and China}

In 1991, the Fifth National Congress of the Laos People's Revolutionary Party determines "a principled comprehensive reform route", proposes to uphold six basic principles containing the party's leadership and the socialist direction, and implements the policy of opening to the outside world. In 2016, the Tenth National Congress of the Laos People's Revolutionary Party put forwards that per capita GDP is expected to reach $\$ 3100$ and achieve $7.5 \%$ GDP growth rate, and the party will strive to reduce the poverty rate to $15 \%$ by 2020 . By then, the net enrollment rate for primary education is projected to reach $99 \%$ and the literacy rate for people aged 15 and over will reach $95 \%$. The infant mortality rate will reduce to 30 per 1,000 and the maternal mortality rate will reduce to 200 per 100,000 .

The Laotian government believes that forestry plays a decisive role in the economic development of Laos. Sustainable forestry and poverty alleviation require sustained international assistance and technical support based on trade. Laos becomes the 158th member of the WTO in February 2013, which is an important step to promote the integration of Laos with the global economy and also an opportunity for forestry development in Laos.

\subsection{China's "Going Out" Strategy and "One Belt and One Road" Strategy provide driving force for cross-border forestry collaboration between Laos and China}

In 1978, China's reform and opening up mainly focused on opening the market and 
introducing foreign technology, funds and management methods. After nearly 40 years of development, China has accumulated numerous industrial energy and has the ability to transfer some mature technology to the international market with demand so as to make up for the lack of domestic resources and markets. China brings out the domestic technology, equipment, services and products to make room for the development of new industries and funds, and forms China's multinational corporations in the international market to participate in international division of labor. Based on this, since twenty-first Century, China actively implements the "going out" strategy.

Since the 16th National Congress of the CPC and the Third Plenary Session of the 16th CPC Central Committee further put forward to speed up the implementation of the "going out" strategy clearly, the transnational operation of Chinese enterprises has entered a new stage of participating in international cooperation and competition on economic and technical in a wider scope, wider field and higher level, and striving to form a powerful multinational corporation.

As a major strategy of opening up to the outside world in the new era, the strategic concept of "One Belt and One Road" is to realize the long-term stability of China's domestic and external environment, especially the surrounding environment. The "One Belt and One Road" strategy takes interoperability as the key and starting point, plans the implementation of a number of key transport infrastructure projects, and basically builds six strategic channels with countries along the routes, promotes trade and investment facilitation, focuses on promoting the mechanism construction and many industrial and agricultural demonstration parks construction, provides the driving force for Laos and China forestry cross-border collaborative development.

\subsection{Cloud platform is the catalyst for the cross-border cooperation strategy of Laos and China forestry.}

The forestry of Laos and China cross-border cooperation strategy has numerous subjects and scattered geographical position. Issues such as information exchange and resource sharing are important problems in the implementation process of the strategy, but the development of computer technology provides a new technical support for solving these problems. The development of cloud services and big data accelerates the process of strategy, which is a catalyst for the implementation of strategy.

\subsection{The external power of the forestry cross-border cooperation strategy in Laos and China}

In the process of globalization, the external environment is constantly changing, the market demand, the competition and the government policies are all dynamic. The impact of these changes on the enterprises is the external environment of the enterprise stimulation, only enterprises adapt to the changes can they survive. The forestry cooperation of Laos and China is still in its initial stage. The Laos country's open degree and market order are not perfect, and Chinese enterprises "Going Out" experience is congenitally deficient, resulting in many problems in the enterprises of Laos and China in the early run on cooperation. From the practice of economic cooperation among developing countries, trade and investment among developing countries should take government behaviors as the forerunner and mobilize national power to coordinate. After both sides understand each other and establish a smooth coordination mechanism, spontaneous enterprise "Going Out" behavior can follow up. In addition, enterprises need to be supported by other entities to help reduce the risk of cross-border operations, such as the 
participation of research institutes, financial institutions and various types of intermediaries. So the external demand of multi agent coordination is an important external power of the strategy.

\subsection{The Internal power of the forestry cross border cooperation strategy in Laos and China}

Laos and China differ in accumulation of multiple factors and resources endowment such as forest resources, capital and technology. Cross-border cooperation can make full use of their respective advantages, especially under the cooperation of multi subject elements. Cooperation between enterprises of Laos and China can realize collaborative sharing in element domain of forest resources capital and technology, and promote the economic development of their respective countries. In particular, the system formed by resources can reduce cost of forestry economic cooperation between Laos and China, reduce collaborative investment between agricultural and forestry enterprises and improve the efficiency of cross-border cooperation in forestry.

\section{Model construction of forestry cross-border collaboration strategy between Laos and China}

\subsection{The pattern design of "overseas in Jiangsu" in forestry cross-border collaboration strategy between Laos and China}

In view of the problem of "fight alone" and "only blooming without fruit" in the process of "Going Out" of Chinese enterprises, in 2014, Zhang Yang ,the chief expert Professor in Jiangsu decision-making consultation research base, proposed the implementation of "overseas Jiangsu " and carry out " attempt to sea, fixed-point landing". The "overseas Jiangsu" model is essentially a cross-border synergy, mainly referring to the multiple needs of technology, capital, talents, projects, and culture in the context of the "One Belt And One Road" strategy, along with national social-economic development along the Jiangsu overcapacity, industrial structure adjustment of the endogenous development needs, integrating resources from all walks of life in Jiangsu province, taking the initiative to go abroad, looking for greater room for development, to seize the overseas Jiangsu highlands. But "Jiangsu" is not limited to "Jiangsu", but refers to a region of China, advocating "fixed-point landing" in the cross-border coordination of the country via a region of China as a unit.

The "overseas Jiangsu" mode of cross-border is cooperated by the government, industry, academia, research, capital and other multi subjects, to form a cooperation network, relying on government guidance and university-industry cooperation, promoted by finance, cooperating with six elements of talent, research, capital, industry and culture, organizing Chinese enterprises to carry out overseas innovation and entrepreneurship which will be contributed to the formation of Jiangsu Overseas Science and Technology Park, Jiangsu Overseas Industrial Park, Jiangsu Overseas Cultural Park , Jiangsu Overseas City as the symbol of "overseas Jiangsu".

\subsection{The pattern characteristics of "overseas Jiangsu" in forestry cross-border collaboration strategy between Laos and China}

I. "Overseas Jiangsu" takes the initiative to expand overseas new space for the provincial units.

"Overseas Jiangsu" is a new carrier for the first overseas expansion of China's 
developed regions. It is based on the provincial (city, district) administrative regions as the unit to set up overseas "Going-Out" agglomeration areas and the main carrier is industrial park. It is gathered by a variety of factors of production, highlighting the characteristics of regional industrial transfer and optimizing the functional layout which is the new space, new forms and new paths of Chinese region's oversea expansion in Laos.

II. The government creates "overseas Jiangsu" construction, guiding Chinese enterprises "hold together the sea, landing point".

"Overseas Jiangsu" is different from "overseas Japan" that "overseas Japan" grew up in the period of Japanese industrial transfer and the scale of overseas assets in Japan has grown which are the results of Japanese companies' "Going Out" construction."Overseas Jiangsu" is the advance behavior of "Going Out", According to the characteristics of regional industrial transfer and the inherent demands of its economic development; the "overseas Jiangsu" is the "Going Out" ex ante behavior, which is the basis of the development of politics, industry, academia, research capital and other multi-agent cooperation. In the special area of Laos, Jiangsu focus on the integration of science and synergy of industrial factors, avoiding the enterprise "fight alone" sea analysis and highlight cross-border coordination.

III. "Overseas Jiangsu" is not only a strategic means of cross-border cooperation in forestry between Laos and China, but also the path of China's regional "One Belt And One Road" strategy.

Forestry cross-border collaboration is a new mode of economic cooperation in forestry transnational operation. "Overseas Jiangsu" is an effective resource, key element and means to bring together cross-border cooperation. The overseas Jiangsu focuses on the strategic matching between the subject and the element in the cooperation area, emphasizing the reciprocity of the relationship between the countries, and fully drives the main elements such as talents, capital, information, technology and resources through the development of their ability to integrate the advantages of mutual development of resources, to achieve the country and the main elements of the complementary advantages and promote the development of cross-border cooperation zone.

\section{3 "Overseas Jiangsu" cross - border collaborative cloud platform design}

The main body of cross-border coordination strategy is multitudinous; all innovation subjects need to rely on information technology for remoting coordination and communication. Cloud platform provides a new train of thought for the effective management of information resources, making full use of hardware resources, software resources and information resources and achieve remote coordination and communication."Overseas Jiangsu" cloud platform model shown in Figure 1.SaaS layer will be directly oriented to the user's role as a service when provided to the user, including application services and basic services, mainly to the government, enterprises and various mobile terminals. PaaS layer will be located in the terminal development environment and platform migration to the cloud as a service when provided to the user, mainly including reusable technology components, middleware in the form of services, such as user management, security management, data management and resource management. IaaS layer will transfer the storage resources and other infrastructure resources to the cloud when provided to users. It carries on the integration to the physical dispersion by shielding the underlying hardware and application software differences to form the hardware and software virtual resource pool (mainly

include server resources, network resources, storage resources, a variety of application software, etc.) 


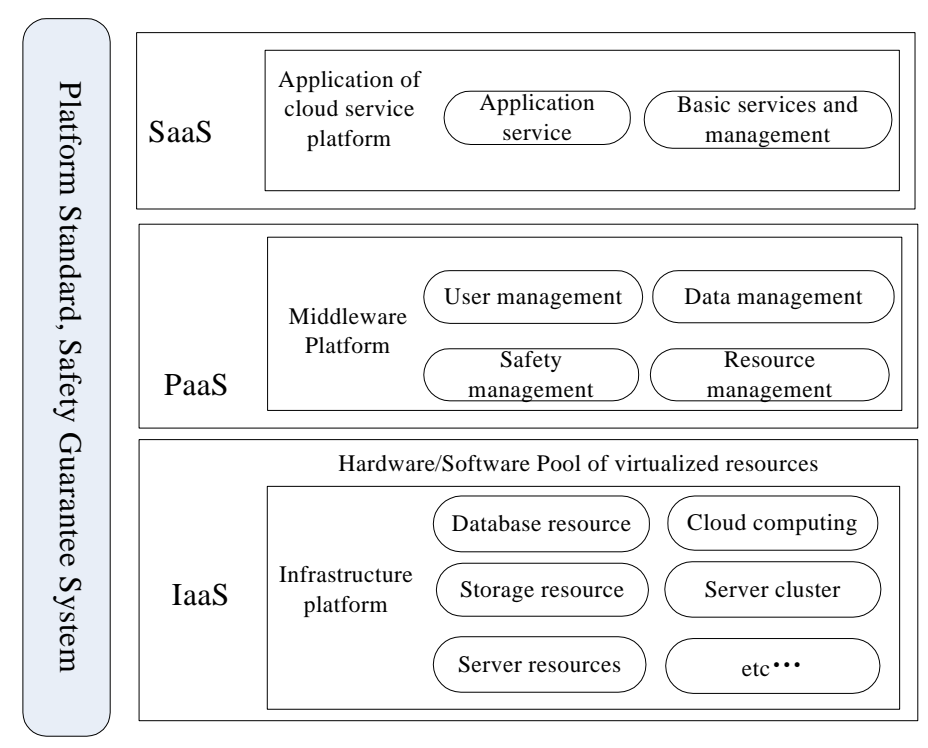

Fig. 1. The frame diagram of "overseas jiangsu" cross-border cooperation cloud platform

\section{$5 \quad$ Policy Advice}

\subsection{Integrating and establishing the "overseas Jiangsu" construction promotion agency.}

The construction of "overseas Jiangsu" is a collaborative network of "Going Out", containing "government, production, learning, research and finance". Its main elements relate to collaborative synergy between enterprises to "Go Out" and the economy of transformation and upgrading, which belongs to the complex system of multi subjects and multi factors synergy. Many departments in charge of internal and external economic development are involved, such as the development and Reform Commission, Department of Commerce, foreign exchange management department and so on. In addition, the system construction and innovation driven of "overseas Jiangsu" are also related to the participation and development of regional public opinion authority (such as the National People's Congress, Laos Congress), science and technology department, educational department, foreign affairs department and other departments. Experience from the process of enterprises to "Go Out" and the economic transformation shows that there are "multi examination and approval, cross management" chaos in overseas investment and economic restructuring initiatives in LaosandChina which indicates that the existing management system can't support the cross-border collaboration strategybetween Laos and China. According to the reference of "one window, management division" management experience in Japanese overseas investment and basics of the actual demand of "overseas Jiangsu" mode, China and Laos are supposed to set up a specialized coordination mechanism participated by the relevant departments as soon as possible; establish special "overseas Jiangsu" forestry construction committee, which are jointly led by Laos and China, aims to program the main elements of the cross-border cooperation comprehensively in the China and Laos and set up a corresponding office of "overseas Jiangsu" forestry construction committee which is responsible for the specific matters of the local cooperation collaboration in the process of forestry cross-border.

5.2 Cultivating social organizations and intermediary service organizations to participate in the cross-border cooperation strategybetween Laos and China 
The social organization is the product of social development which should undertake the function of linking the workers, residents, citizens, government and social, balance the interests and rights between the workers and the enterprises, and play the role of social stabilizers and buffers. Its role and function can't be substituted by government organization. The higher the degree of social civilization, the more developed social organization and the greater the role of social promotion. As a part of the social activities, the Laos-China's forestry cross-border cooperation can't be separated from the promotion and function of social organizations. At present, there are many forestry industry association and professional associations in China and Laos. These social organizations play an important role in promoting the Laos-China's forestry enterprises cooperation. Professional organizations that specialized in providing consulting and training services for the nature of enterprise management also play an important role in promoting enterprises to "Going Out" and upgrading. However, "overseas Jiangsu" is a new mode of forestry cross-border cooperative and coordination network containing "government, production, learning research and finance". Its construction cannot achieve without the participation of forestry association and some professional intermediary service institutions, such as investment banking, international law firms and many otherservices institutions ofintellectual property transactions, technology transfer and the transfer of property rights. So it is urgent to accelerate the training of social organizations and intermediary service agencies in forestry construction field of "overseas Jiangsu" and the cultivating of numerous professional talents to provide professional services for "overseas Jiangsu" forestry construction.

\subsection{Construction of the application system of cross-border cooperation in the development of the Laos-China forestry cross-border collaboration}

The development of the modern economy relies on the application of computer technology, and information technology becomes more and more important in the economic management of forestry. Laos-China's forestry cross-border coordination strategy is involved in many subjects and large amount of data. It is proper constructing a cooperative database, establishing a cloud platform, and designing integrated system of Laos-China forestry cross-border collaboration to ensure the implementation of Laos-China's forestry cross-border collaboration strategy.

\section{References}

1. Ansoff, H.: Corporate Strategy. Revised edition, New York: McGraw Hill Company, 35-83(1987).

2. Haken H. Advanced synergeties. GuoZhian, translated. Beijing: China Science Publishing \& Media, Ltd, 23-54(1989).

3. Haken H. Erfolgsgeheimnisse der Natur: Synergetik, die Lehre vom Zusammenwirken. Ling Fuhua, translated. Shanghai: Shanghai Century Publishing Group (2005).

4. Greif I. Computer-Supported Cooperative Work: A Book of Readings. San Mateo, Calif.: Morgan Kaufmann Publishers, 5-12(1988).

5. Wang Zhao-jun. Consideration on synergetic operation of Forestry Ecological System and Forestry Industry System. Forestry Economics, 01:40-45(2001).

6. YANG Jia-meng ZHANG Zhi-guang. A study on extension and expansion of foresty industrial chain base on Supply and Demand Collaborative. Commercial Research, 02:36-40(2010).

7. YANG Fan; ZHAO Shitong; HUANG Weiwei et al. The Evaluation of Coordinated Development of Forestry Composite System after the Collective Forest Tenure in China_-Taking Sichuan province as an example. Issues of Forestry Economics, 02:159-165(2015).

8. Li denglu.On the management of forestry economy by using computer technology. China Forestry Industry, 07:106-107(2016).

9. Varma V K, Ferguson I, Wild I. Decision support system for the sustainable forest management. Forest ecology and management, 128(1): 49-55(2000).

10. Pompa-García, Marín, et al. A system for calculating the merchantable volume of oak trees in the northwest of the state of Chihuahua, Mexico. Journal of Forestry Research, 
20(4): 293-300(2009).

11.ZHU Qi-ming. The Formation and Implementation of transnational corporations Synergy strategy. Contemporary Finance \& Economics, 05:80-84 (2004).

12. Wang Chunzhi, Gao Qiang, ;Heiko Gebauer. Study on Service Spare Parts Trans-bordering Logistic Collaborating System Based on the Grounded Theory. Management Review, v.2702:178-186+208(2015). 